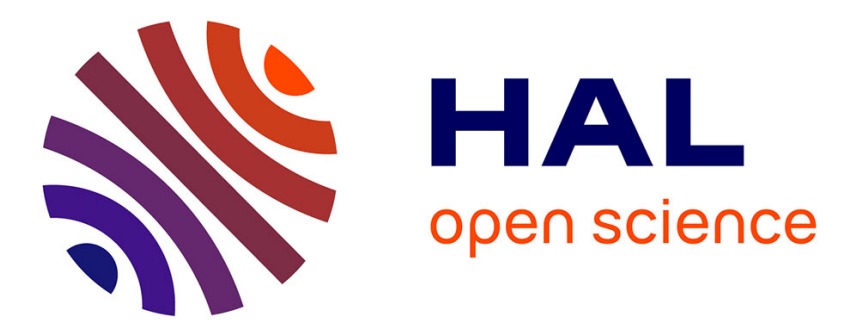

\title{
The influence of confinement on the bearing capacity of strip footings
}

\author{
Jean Salençon
}

\section{To cite this version:}

Jean Salençon. The influence of confinement on the bearing capacity of strip footings. Comptes Rendus Mécanique, 2002, 330, pp.319-326. 10.1016/S1631-0721(02)01459-6 . hal-00111345

\section{HAL Id: hal-00111345 \\ https://hal.science/hal-00111345}

Submitted on 9 Jul 2019

HAL is a multi-disciplinary open access archive for the deposit and dissemination of scientific research documents, whether they are published or not. The documents may come from teaching and research institutions in France or abroad, or from public or private research centers.
L'archive ouverte pluridisciplinaire HAL, est destinée au dépôt et à la diffusion de documents scientifiques de niveau recherche, publiés ou non, émanant des établissements d'enseignement et de recherche français ou étrangers, des laboratoires publics ou privés. 


\title{
The influence of confinement on the bearing capacity of strip footings
}

\author{
Jean Salençon \\ École polytechnique, Laboratoire de mécanique des solides, 91128 Palaiseau cedex, France
}

\begin{abstract}
The bearing capacity for a strip footing acting on a soil foundation with rigid boundaries at a finite distance is investigated within the framework of the Yield design theory both for a purely cohesive soil and for a frictional soil. It is shown that the analysis can be performed simply by referring to already existing results concerning the bearing capacity of a strip footing on a soil layer with limited thickness. Each bearing capacity factor in Terzaghi formula is increased by a factor that increases when the distance of the rigid boundary to the edge of the footing decreases. The bearing capacity is proved to be the more sensitive to this confining effect as the friction angle of the soil increases. From a physical point of view this theoretical analysis would show that, when effective, confinement reduces the depth of the soil layer involved in the collapse mechanism.
\end{abstract}

soils / bearing capacity / confinement / foundation / Terzaghi / yield design

\section{Effet du confinement sur la capacité portante d'une fondation superficielle}

Résumé On étudie la force portante d'une fondation superficielle sur un demi-espace limité horizontalement par des parois rigides. On se place dans le cadre de la théorie du calcul à la rupture. On montre que l'analyse peut être menée simplement à partir des résultats déjà existants au sujet de la portance d'une fondation sur une couche de sol d'épaisseur limitée. Chaque coefficient dans la formule de Terzaghi est multiplié par un facteur qui croit quand la distance de la paroi rigide au bord de la fondation diminue. Cet effet de confinement est d'autant plus sensible que l'angle de frottement du sol est grand. Du point de vue physique cette analyse théorique prouverait que le confinement a pour effet de réduire la profondeur de la couche de sol impliquée dans le mécanisme de ruine.

sols / calcul à la rupture / fondation / force portante / Terzaghi

\section{The problem under investigation}

The paper is concerned with the theoretical determination of the bearing capacity of a rigid strip footing under axial loading, acting on a homogeneous soil foundation with infinite thickness. The width of the footing is denoted $B=2 b$. The soil foundation is assumed to be limited in both horizontal directions at a distance $L$ from the edge of the footing by rigid walls. The contact between the footing and the soil 
on the one side and between the soil and the rigid walls on the other is assumed to be perfectly rough. The goal of the paper is to give a method for assessing the correction factor to be applied to the classical bearing capacity factors to take into account the influence of confinement due to the limited width of the soil foundation as a function of $L / b$. The theoretical framework is given by the theory of yield design [1] or limit analysis with main purpose of obtaining upper bound estimates for the effect of confinement. The foundation soil is isotropic. It is characterised first by a Tresca strength criterion with cohesion $c_{\mathrm{u}}$, then by a Coulomb strength criterion with cohesion $c$ and friction angle $\phi$.

\section{Strip footing acting on a purely cohesive soil}

\subsection{The problem under consideration}

The axial force acting on the footing is denoted $F$ (more precisely, $F$ is the axial force per unit transversal length acting on the footing). The problem is classically treated as 2-dimensional.

The bearing capacity is $p_{\mathrm{ult}}=F / B$. Dimensional analysis proves that for the problem at hand $p_{\mathrm{ult}}$ takes the form:

$$
p_{\text {ult }}=c_{\mathrm{u}} K_{c}\left(\frac{L}{b}\right) N_{c} \quad \text { with } N_{c}=\pi+2 \text { and } K_{c}(\infty)=1
$$

For an unlimited soil foundation $(L / b \rightarrow \infty)$ the exact value of the bearing capacity is derived from the classical velocity field of the Prandtl solution for the kinematic approach [2]. For the static approach the stress-fields constructed by Bishop [3] or by Shield [4] or by Sayir and Ziegler [5] may be used. Fig. 1 sketches the stress field given by Shield and the velocity field. The length of the uplifted wave $A D$ in the velocity field is denoted $w$ and we have $w / b=C_{c}=2$.

\subsection{Static approach}

In the case of a soil foundation bounded by rough rigid walls at a distance $L$ from the edges, a static approach is obtained, whatever $L / b \geqslant 0$, through considering the restriction of the stress-field in Fig. 1 to the bulk of soil between the walls. The friction condition at the interface between the walls and the soil is fulfilled since the normal stress acting on the rough wall is compressive everywhere: whatever $L / b \geqslant 0$ the wall will intersect the three zones I, II, III in the Shield discontinuous stress-field; in zone I, $\sigma_{y y}$ is constant and compressive: $\sigma_{y y}=-2 c_{\mathrm{u}}$; zone II is a centred fan where both principal stresses are compressive and therefore $\sigma_{y y}$ is compressive; in zone III, the principal stresses are $\sigma_{x x}$ and $\sigma_{y y}$ which are independent of $x$ and $y$ respectively and such that $\sigma_{x x}-\sigma_{y y}=2 c_{\mathrm{u}}$; introducing angle $\alpha$ as indicated in Fig. 1, it comes out

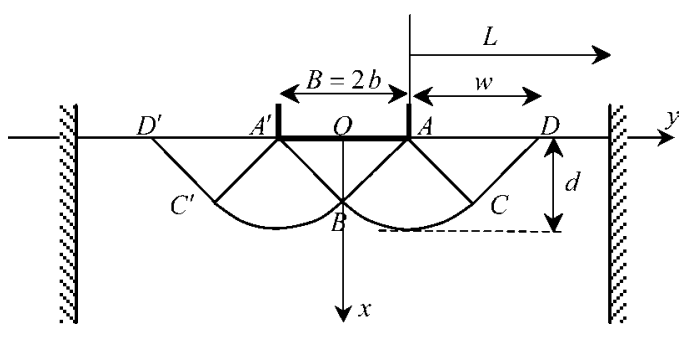

Figure 1. Prandtl solution [2] and extension of Prandtl's stress-field by Shield [4].

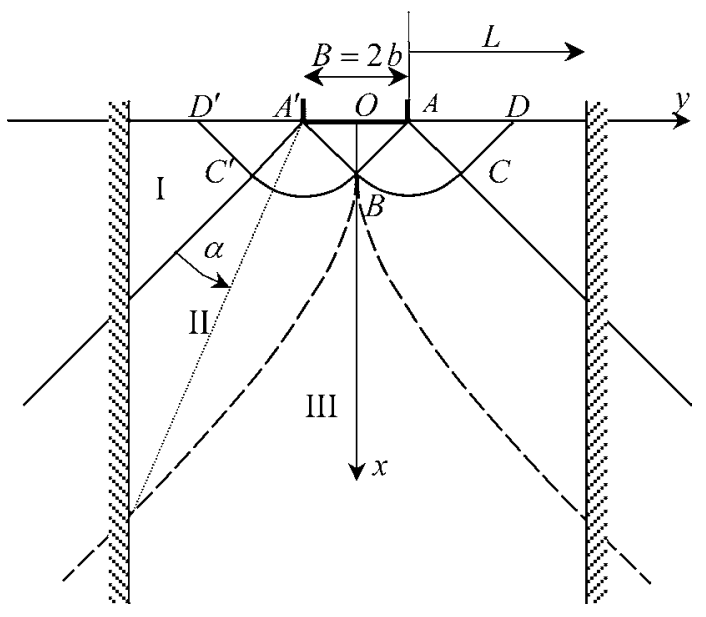


explicitly that along the wall in zone III we have $-2 c_{\mathrm{u}} \leqslant \sigma_{y y} \leqslant-2 c_{\mathrm{u}}(1+\alpha-\sin \alpha)$, which proves that $\sigma_{y y}$ is compressive. From this static approach it follows that:

$$
\forall \frac{L}{b} \geqslant 0, \quad K_{c}\left(\frac{L}{b}\right) \geqslant 1
$$

2.3. $L / b \geqslant C_{c}$

It also appears that the classical virtual velocity field in Fig. 1 is still valid for a kinematic approach as long as $L / b \geqslant C_{c}=2$. From which it follows that:

$$
\forall \frac{L}{b} \geqslant C_{c}=2, \quad K_{c}\left(\frac{L}{b}\right)=1
$$

2.4. $0 \leqslant L / b<C_{c}$

Investigating the range $0 \leqslant L / b<C_{c}=2$, we refer to the solution given by Johnson and Kudo [6] and used by Mandel and Salençon [7] for the determination of the bearing capacity of a surface footing on a soil layer of limited thickness $h$, which is presented in Fig. 2. The contact between the soil layer and the rigid bedrock is assumed to be perfectly rough. The slip-line field starts in the same way as in the Prandtl solution and is extended under the footing taking into account the perfectly rough contact conditions under the footing and at the bedrock until it reaches the axis of the footing at an angle of $\pi / 4$. The geometric ratio $w / h$ in this slip-line field comes from Prandtl's characteristic fan at point $A$ and is a constant whatever $B / h$ :

$$
\forall \frac{B}{h}, \quad \frac{w}{h}=\lambda_{c}=\sqrt{2}
$$

This slip-line field provides both a velocity field for the kinematic approach and a stress field for the static approach from which the exact value of the bearing capacity of the footing was derived as a function of $B / h$ with tabulated values of the correction factor $F_{c}(B / h)$ :

$$
p_{\mathrm{ult}}=c_{\mathrm{u}} F_{c}\left(\frac{B}{h}\right) N_{c}=c_{\mathrm{u}} F_{c}\left(\lambda_{c} \frac{B}{w}\right) N_{c}=c_{\mathrm{u}} F_{c}\left(\frac{B \sqrt{2}}{w}\right) N_{c}
$$

In order to obtain an upper bound estimate to the correction factor due to confinement in Eq. (1) when $0 \leqslant L / b<C_{c}=2$, given $L / b$, we simply consider the Johnson and Kudo slip-line field for which $w / b=L / b$. The same velocity field as in Fig. 2 provides a kinematic approach for the problem under present investigation (Fig. 3), the whole soil mass beneath SRICD (and sym.) being motionless. (It is worth noting that, in this case, the slip-line field exhibits envelopes for the characteristic lines within the soil mass: since the slip-line field is only used for the derivation of a velocity field, there is no objection to this.) Without any further calculation but referring to the tabulated values of $F_{c}(B / h)$ an upper bound is obtained for $K_{c}(L / b)$ which is presented in Fig. 3:

$$
K_{c}\left(\frac{L}{b}\right) \leqslant F_{c}\left[2 \lambda_{c}\left(\frac{L}{b}\right)^{-1}\right]=F_{c}\left(2 \sqrt{2} \frac{b}{L}\right)
$$

Figure 2. Strip footing on a purely cohesive soil layer of limited thickness [7].

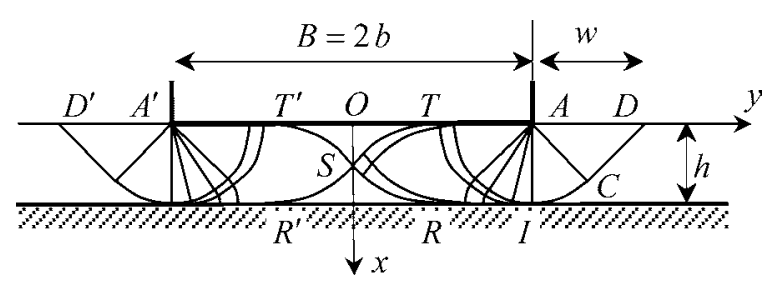



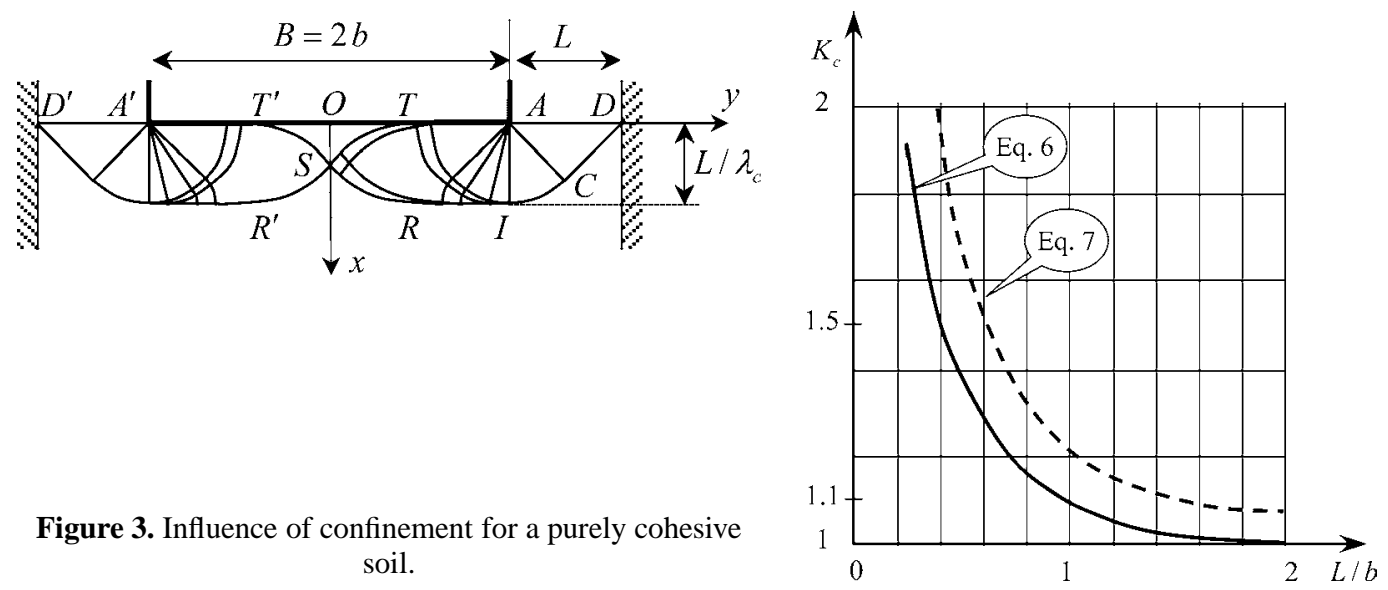

Figure 3. Influence of confinement for a purely cohesive soil.

which proves significantly poorer than Eq. (6).

\section{Strip footing acting on a frictional soil}

\subsection{Classical results}

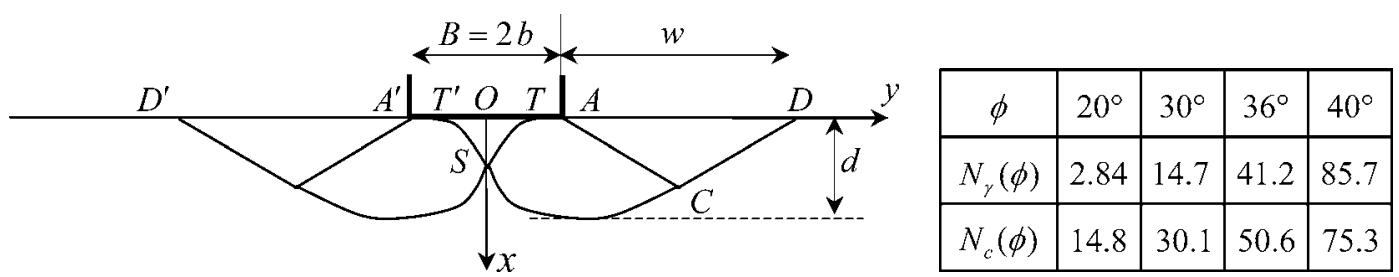

Figure 4. Lundgren and Mortensen solution [8] and values of $N_{\gamma}(\phi)$ and $N_{c}(\phi)$ according to [7].

We now address the same problem for an isotropic frictional soil defined through a Coulomb strength criterion with cohesion $c$ and friction angle $\phi$. The bearing capacity of a strip footing on an unlimited soil foundation is usually written following Terzaghi's formula where the theorem of corresponding states is taken into account:

$$
p_{\text {ult }}=\frac{1}{2} \gamma B N_{\gamma}(\phi)+c N_{c}(\phi)+q N_{q}(\phi), \quad N_{q}(\phi)=1+N_{c}(\phi) \tan \phi
$$

The networks of characteristic lines for the determination of $N_{c}(\phi)$ are classical Prandtl's fields for a weightless frictional material. As regards $N_{\gamma}(\phi)$ the solution was given by Lundgren and Mortensen [8]: the characteristic network (Fig. 4) proceeds from the classical solution to the problem of the limit equilibrium of a wedge at point $A$, about which some characteristic features must be recalled. It is self-similar with respect 
Figure 5. Characteristic network for the calculation of $N_{\gamma}(B / h, \phi)[7]$.

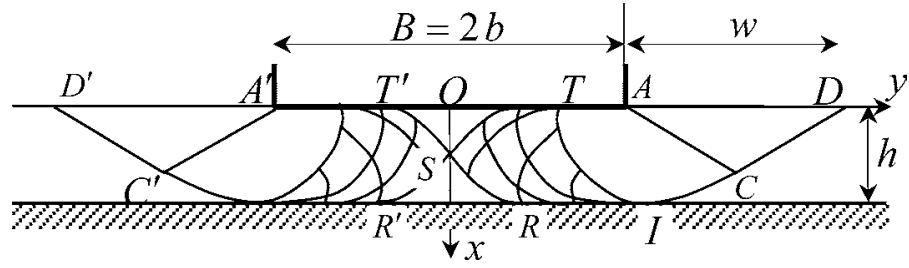

to $A$, exhibiting no singularity at point $A$ it must be determined through a trial-and-error method starting from the interface under the footing. For the applications to be made it has been necessary to recalculate this solution using the initial values for the trial-and-error method available in [7].

As regards $N_{c}(\phi)$ the solution can be interpreted as a static approach: the stress field was extended in the whole volume of the foundation soil through Shield's method [9]. It is also a kinematic approach within the theory of yield design since a relevant velocity field can be obtained from the classical equations for the velocity along the characteristic lines in the case of a Coulomb strength criterion. Concerning $N_{\gamma}(\phi)$ the solution was proved to be a kinematic approach (Bonding [10]). The extension of the stress field may still be missing. Fig. 4 gives the values of the bearing capacity factors according to [7] for the values of $\phi$ that will be considered later on.

When the foundation is a soil layer of limited thickness the same decomposition applies in Eq. (9) as in Eq. (8) with the introduction of the corresponding bearing capacity factors, functions of $B / h$ which were determined in the same way as for the purely cohesive soil [7]: $N_{\gamma}(B / h, \phi)$ and $N_{c}(B / h, \phi)$. The characteristic networks are quite similar to Fig. 2 as presented in Fig. 5 for the determination of $N_{\gamma}(B / h, \phi)$.

$$
\left\{\begin{array}{l}
p_{\text {ult }}=\frac{1}{2} \gamma B N_{\gamma}\left(\frac{B}{h}, \phi\right)+c N_{c}\left(\frac{B}{h}, \phi\right)+q N_{q}\left(\frac{B}{h}, \phi\right) \\
N_{q}\left(\frac{B}{h}, \phi\right)=1+N_{c}\left(\frac{B}{h}, \phi\right) \tan \phi
\end{array}\right.
$$

The results are available in the form of tabulated correction factors to be applied to $N_{\gamma}(\phi)$ and $N_{c}(\phi)$ :

$$
N_{\gamma}\left(\frac{B}{h}, \phi\right)=F_{\gamma}\left(\frac{B}{h}, \phi\right) N_{\gamma}(\phi), \quad N_{c}\left(\frac{B}{h}, \phi\right)=F_{c}\left(\frac{B}{h}, \phi\right) N_{c}(\phi)
$$

\subsection{The problem under consideration}

The same arguments as above prove that the bearing capacity of a footing on a soil foundation with unlimited thickness and bounded horizontally by rigid walls at a distance $L$ from the edge of the footing is estimated in a conservative manner through a Terzaghi formula similar to Eq. (9), where the bearing capacity factors are functions of $L / b$ and $\phi$ :

$$
\left\{\begin{array}{l}
p_{\mathrm{ult}}=\frac{1}{2} \gamma B N_{\gamma}\left(\frac{L}{b}, \phi\right)+c N_{c}\left(\frac{L}{b}, \phi\right)+q N_{q}\left(\frac{L}{b}, \phi\right) \\
N_{q}\left(\frac{L}{b}, \phi\right)=1+N_{c}\left(\frac{L}{b}, \phi\right) \tan \phi
\end{array}\right.
$$

Correction factors $K_{\gamma}(L / b, \phi)$ and $K_{c}(L / b, \phi)$ are introduced to account for the influence of confinement:

$$
N_{\gamma}\left(\frac{L}{b}, \phi\right)=K_{\gamma}\left(\frac{L}{b}, \phi\right) N_{\gamma}(\phi), \quad N_{c}\left(\frac{L}{b}, \phi\right)=K_{c}\left(\frac{L}{b}, \phi\right) N_{c}(\phi)
$$



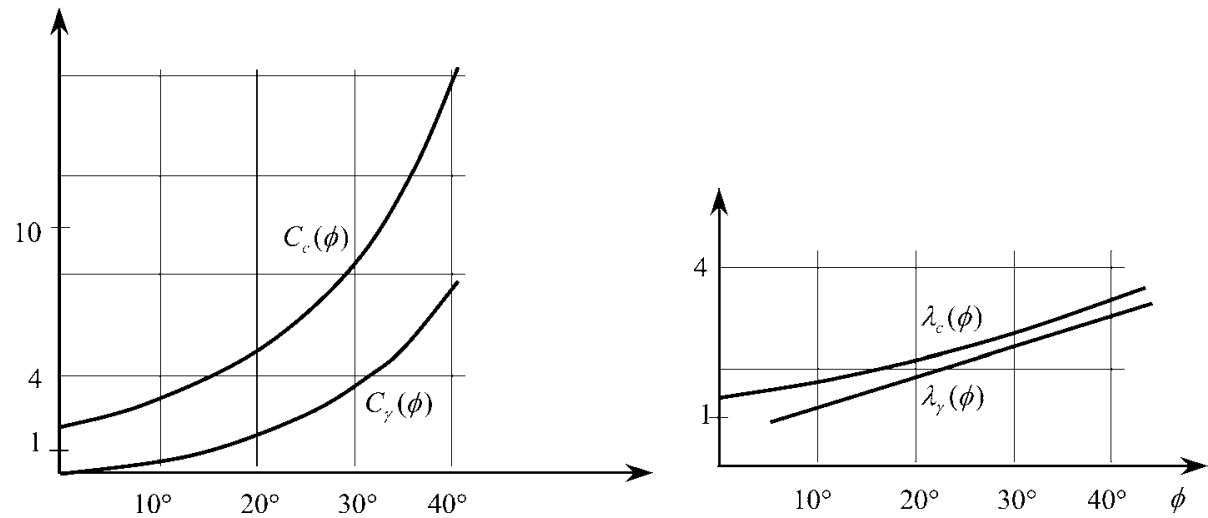

Figure 6. Geometric ratios in the Lundgren and Mortensen solution and in the Prandtl solution.

3.3. Influence of confinement on the $N_{\gamma}$ term: $L / b \geqslant C_{\gamma}(\phi)$

Examining first the $N_{\gamma}$ term, we consider a strip footing acting on a frictional soil foundation with no cohesion.

The Lundgren and Mortensen solution being characterised with the ratios $w / d=\lambda_{\gamma}(\phi)$ and $w / b=$ $C_{\gamma}(\phi)$ that are presented in Fig. 6, it follows, assuming the extension of the stress-field has been achieved for this solution, that:

$$
\forall \frac{L}{b} \geqslant C_{\gamma}(\phi), \quad K_{\gamma}\left(\frac{L}{b}, \phi\right)=1
$$

3.4. Influence of confinement on the $N_{\gamma}$ term: $0 \leqslant L / b<C_{\gamma}(\phi)$

For the range $0 \leqslant L / b<C_{\gamma}(\phi)$, given $L / b$, we refer to the solution to the problem of the bearing capacity on a soil layer of limited thickness for which $w / b=L / b$ (Fig. 7). The corresponding network of characteristic lines provides a relevant velocity field for the problem under investigation within the framework of the theory of yield design. The corresponding value of $p_{\text {ult }}$ is obtained from the first term in Eq. (9), by referring to the tabulated values of $F_{\gamma}(B / h, \phi)$ once the correspondence between $L / b$ and $B / h$ is known. The solution to the wedge problem being self-similar with respect to point $A$, the geometric ratio $w / h$ is a constant whatever $L / b<C_{\gamma}(\phi)$, viz. $w / h=\lambda_{\gamma}(\phi)$. Hence the upper bound for the correction factor due to confinement is written:

$$
0 \leqslant \frac{L}{b}<C_{\gamma}(\phi), \quad K_{\gamma}\left(\frac{L}{b}, \phi\right) \leqslant F_{\gamma}\left[2 \lambda_{\gamma}(\phi)\left(\frac{L}{b}\right)^{-1}, \phi\right]
$$

It is presented in Fig. 7 for some realistic values of $\phi: 20^{\circ}, 30^{\circ}, 36^{\circ}$ and $40^{\circ}$.

\subsection{Confining effect on the $N_{c}$ term: $L / b \geqslant C_{c}(\phi)$}

As regards the effect of confinement on the $N_{c}$ term in Eq. (11), the analysis strictly follows the same path as above, with the simplification that the characteristic line network being derived from Prandtl's solution for the frictional material the geometric ratios $w / d=\lambda_{c}(\phi)$ and $w / b=C_{c}(\phi)$ are explicit functions of $\phi$ (Fig. 6):

$$
\begin{aligned}
& \frac{w}{d}=\lambda_{c}(\phi)=\sqrt{2}\left[\cos \left(\frac{\phi}{2}\right)-\sin \left(\frac{\phi}{2}\right)\right] \exp \left[\left(\frac{\pi}{4}-\frac{\phi}{2}\right) \tan \phi\right] \\
& \frac{w}{b}=C_{c}(\phi)=2 \sqrt{(1+\sin \phi) /(1-\sin \phi)} \exp \left[\left(\frac{\pi}{2}\right) \tan \phi\right]
\end{aligned}
$$




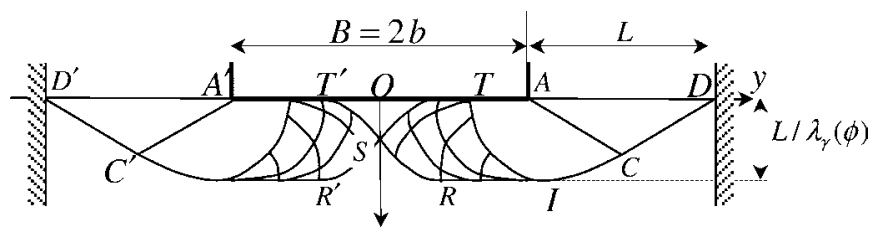

Figure 7. Influence of confinement on the $N_{\gamma}$ term.

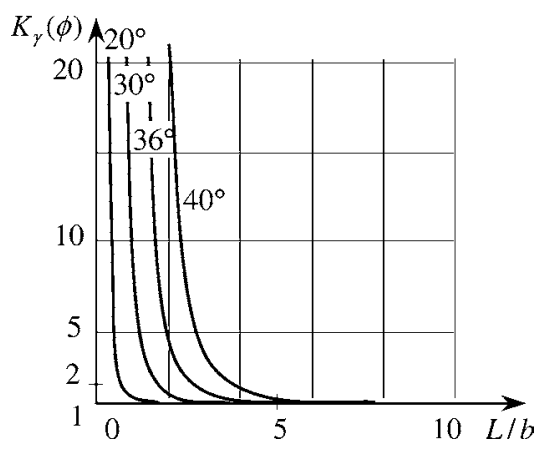

Again, it comes out easily that:

$$
\forall \frac{L}{b} \geqslant C_{c}(\phi), \quad K_{c}\left(\frac{L}{b}, \phi\right)=1
$$

3.6. Confining effect on the $N_{c}$ term: $L / b<C_{c}(\phi)$

The assessment of the effect of confinement on the $N_{c}$ term in Eq. (11) when $L / b<C_{c}(\phi)$ does not need a long comment. Given $L / b$, we refer to the solution to the bearing capacity problem for the weightless soil layer with limited thickness for which the network of characteristic lines fits exactly within the horizontal bounds of the soil foundation. It provides a relevant velocity field for the problem under consideration and the upper bound for the correction factor $K_{c}(L / b, \phi)$ is derived from the tabulated values of $F_{c}(B / h, \phi)$ :

$$
K_{c}\left(\frac{L}{b}, \phi\right) \leqslant F_{c}\left[2 \lambda_{c}(\phi)\left(\frac{L}{b}\right)^{-1}, \phi\right]
$$

which is presented in Fig. 8 for the same values of $\phi: 20^{\circ}, 30^{\circ}, 36^{\circ}$ and $40^{\circ}$ as $K_{\gamma}(L / b, \phi)$.

Figure 8. Influence of confinement on the $N_{c}$ term.

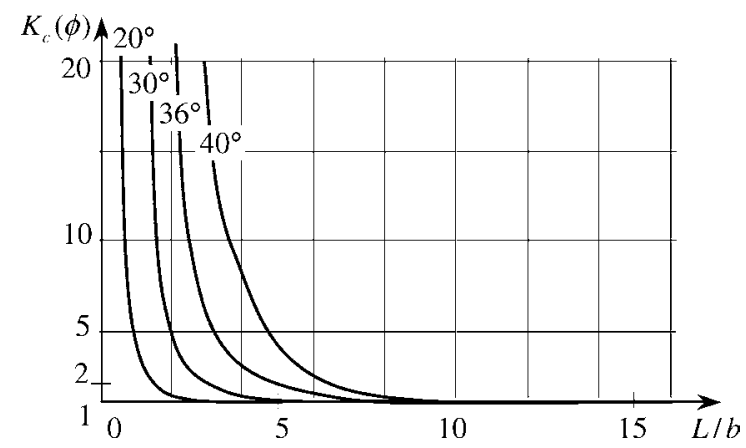

\section{Conclusion and comments}

The analysis described in the preceding Sections shows that upper bound estimates for the assessment of the confining effect due to the limited horizontal width of the soil foundation can be conveniently made by revisiting classical solutions to the problem of the bearing capacity of a surface footing on a soil layer of limited thickness. From the physical point of view, this means that the presence of the rigid walls, when they are close enough to the footing, reduces the thickness of the zone where the soil is concerned with deformation at collapse.

In the case of the purely cohesive material, the increase of the bearing capacity due to this confining effect remains small for realistic values of $L / b$. 
For the frictional material the conclusions are somewhat different. It comes out clearly from Fig. 6 that both $C_{\gamma}(\phi)$ and $C_{c}(\phi)$ are functions which increase quickly with $\phi$. It follows that the bearing capacity is the more sensitive to the influence of the rigid walls which bound the soil foundation as $\phi$ increases. Given $\phi$, the correction factors $K_{c}(L / b, \phi)$ and $K_{\gamma}(L / b, \phi)$ are functions of $L / b$ which start tangentially to the horizontal axis and increase sharply when $L / b$ decreases to zero. It follows that for realistic values of $L / b$ the increase of the bearing capacity due to the confining effect becomes more and more significant as $\phi$ increases. From Fig. 6 we see that in any case $C_{c}(\phi)$ is significantly greater than $C_{\gamma}(\phi)$. Comparing Figs. 7 and 8 shows that given $L / b$ and $\phi$ within the range we have been considering $\left(20^{\circ} \leqslant \phi \leqslant 40^{\circ}\right), K_{c}(L / b, \phi)$ is, by far, higher than $K_{\gamma}(L / b, \phi)$. One may also notice that in the same time $\lambda_{c}(\phi)$ is but slightly greater than $\lambda_{\gamma}(\phi)$, which shows that, given $L$, the thickness of the soil layers involved in the collapse mechanisms for the $N_{c}$ term and for the $N_{\gamma}$ term respectively would be of the same order of magnitude.

The same method as described in this paper can be applied to the analysis of the effect of confinement on the bearing capacity of circular footings, referring to the solution to the problem of the bearing capacity of circular footings on a soil layer with limited thickness, which was given in [11].

\section{References}

[1] J. Salençon, An introduction to the yield design theory and its applications to soil mechanics, European J. Mech. A 9 (5) (1990) 477-500.

[2] L. Prandtl, Anwendungsbeispiele zu einem Henckyschen Satz über das plastische Gleichgewicht, Z. Angew. Math. Mech. 3 (1923) 401.

[3] J.F.W. Bishop, On the complete solution to problems of deformation of a plastic rigid material, J. Mech. Phys. Solids 2 (1) (1953) 43-53.

[4] R.T. Shield, Plastic potential theory and Prandtl bearing capacity solution, Trans. ASME J. Appl. Mech. 21 (1954) 193-194.

[5] M. Sayir, H. Ziegler, Zum Prandtlschen Stampelproblem, Ing. Arch. 36 (5) (1968) 294-302.

[6] W. Johnson, H. Kudo, The compression of a rigid perfectly plastic material between rough parallel dies of unequal width, Internat. J. Mech. Sci. 1 (4) (1960) 336.

[7] J. Mandel, J. Salençon, Force portante d'un sol sur une assise rigide (étude théorique), Géotechnique 22 (1) (1972) 79-93.

[8] H. Lundgren, K. Mortensen, Determination of the bearing capacity of continuous footings on sand, in: Proc. 3rd Int. Conf. Soil Mech., Vol. 1, Zurich, 1953, pp. 409-412.

[9] J. Salençon, Sur le prolongement statique des champs de Prandtl pour le matériau de Coulomb, Arch. Mech. Stos. 25 (4) (1973) 643-648.

[10] A. Bonding, Kinematical admissibility of the pure $N \gamma$ rupture figure, in: Proc. 9th Int. Conf. Soil Mech. 1 Found. Engrg., Vol. 1, Tokyo, 1977, pp. 415-418.

[11] J. Salençon, M. Matar, Capacité portante des fondations superficielles circulaires (Bearing capacity of axially symmetrical shallow foundations), J. Mec. Théor. Appl. 1 (2) (1982) 237-267. 